\title{
EXPLORE
}

\section{Sistem Informasi Rumah Kost Berbasis Web Studi Kasus pada Paviliun Sejahtera}

\author{
Agung Rahmatillah, Tomi Saputra, Wuwuh Bekti Hartiningsih \\ Program Studi Sistem Informasi \\ Universitas Mercu Buana Jakarta \\ Jakarta, Indonesia \\ agungest@gmail.com, tomisaputradewantara@gmail.com,wuwuh.hartiningsih@gmail.com
}

\begin{abstract}
In the development of the digital era that is so fast today, the benefits can be felt both from young people to the elderly who can easily use technology and the internet today, the internet has become an important part of daily activities because with the internet all the information needed can be searchable and can help internet users to stay connected with other people who have long distances to communicate directly. However, there are still many who have not used the internet as a medium for transactions. Prosperous Pavilion is one of the many boarding houses in Indonesia that have not used the internet as a transaction medium in it. In making room booking transactions, payments are made manually without involving the internet, making it difficult for residents of the pavilion to see the history of payment transactions, communicating with landlords, and so on.
\end{abstract}

Keywords: Internet, Booking and Paviliun Sejahtera

\begin{abstract}
Abstrak- Perkembangan sistem informasi yang semakin cepat bisa dimanfaatkan dengan baik melalui banyak hal dalam sistem, namun beberapa pengelola dan calon penyewa usaha sewa rumah kos dan rumah kontrakan masih mengalami kesulitan dalam memiliki suatu sistem yang terintegrasi. Banyak diantara mereka masih melakukan pemesanan rumah kos secara langsung di lokasi tempat kos berada dan informasi yang terbatas mengenai tipe dan fasilitas kamar yang tersedia. Paviliun Sejahtera merupakan salah satu dari sekian banyak rumah kos yang ada di Indonesia yang belum memanfaatkan internet sebagai media transaksi di dalamnya. Dalam melakukan transaksi pemesanan kamar, pembayaran dilakukan secara manual tanpa memperlibatkan internet sehingga mempersulit penghuni paviliun untuk melihat history transaksi pembayaran, melakukan komunikasi dengan pemilik kontrakan, dan sebagainya. Metode pengembangan sistem informasi yang digunakan adalah metode waterfall yaitu analisa kebutuhan, perancangan sistem, implementasi, pengujian \& testing. Dan analisis SWOT (Strength, Weakness, Opportunities, Threats) untuk menemukan sumber masalah. Metode pengumpulan data yaitu observasi dan studi pustaka. Sistem Informasi Rumah Kost Berbasis Web Studi Kasus Pada Paviliun Sejahtera yang mampu memberikan informasi secara lengkap, yang dapat diakses baik melalui browser pada komputer, maupun browser mobile. Dalam pembuatan website ini menggunakan framework PHP CodeIgniter sebagai komponen dari perancangan sistem. Dari hasil penelitian ini, diharapkan dapat membantu Pemilik Paviliun dan penyewa dalam melakukan proses penyewaan rumah kos dengan cara yang lebih tersttuktur dan efisien.
\end{abstract}

Kata Kunci: Sistem Informasi Paviliun Sejahtera, Penyewaan, Universitas Mercu Buana

\section{Pendahuluan}

Paviliun Sejahtera merupakan rumah kost yang memiliki 180 kamar dan terletak di kabupaten cibitung, bekasi. Saat ini hanya sekitar 30\% dari kamar kost yang sudah terisi oleh penyewa kamar kost. Kurangnya media promosi dari paviliun menjadikan paviliun ini kurang diketahui oleh masyarakat luas. Sehingga menyebabkan banyaknya kamar kost yang belum terisi. Dalam menjalankan transaksi pemesanan kamar dan pembayaran masih dilakukan secara manual atau langsung sehingga keamanan transaksi tersebut kurang terjamin.

Dengan masalah yang di hadapi oleh Paviliun Sejahtera, maka dibutuhkan sebuah sistem informasi berbasis web. Pemanfaatan sistem dan teknolgi informasi secara digital diharapkan mampu memberikan solusi terhadap permasalahan yang ada. Teknologi dan informasi yang dirancang dapat memberikan gambaran kepada masyarakat secara umum, dan kepada si pencari tempat tinggal khususnya. Sistem ini menawarkan informasi yang detil dan lengkap baik informasi harga, fasilitas, lokasi, gambar dalam hunian dan luar hunian. Dan mengalihkan transaksi pemesanan dan pembayaran kamar dari yang awalnya secara langsung menjadi secara online juga dengan transfer bank. Tujuan dari Penelitian ini diharapkan dengan sistem informasi yang akan dibuat dapat membantu dalam aktifitas Paviliun Sejahtera dalam 
memberikan pelayanan kepada penghuni maupun pengunjung paviliun.

\section{Metodologi}

Metode penelitian yang digunakan dalam penelitian ini, penulis melakukan pengumpulan data melalui cara:

1. Observasi
Penulis melakukan pengamatan langsung ke Paviliun Sejahtera untuk mengetahui sistem penyewaan Paviliun dan tipe Paviliun,serta sarana dan prasarana yang ada.

2. Studi Pustaka

Dalam metode ini penulis mencari informasi dari dari berbagai sumber pendukung, mulai dari buku-buku dan artikel, serta jurnal terkait dari internet untuk dijadikan sebagai refrensi.

\section{Diagram Alir Penelitian}

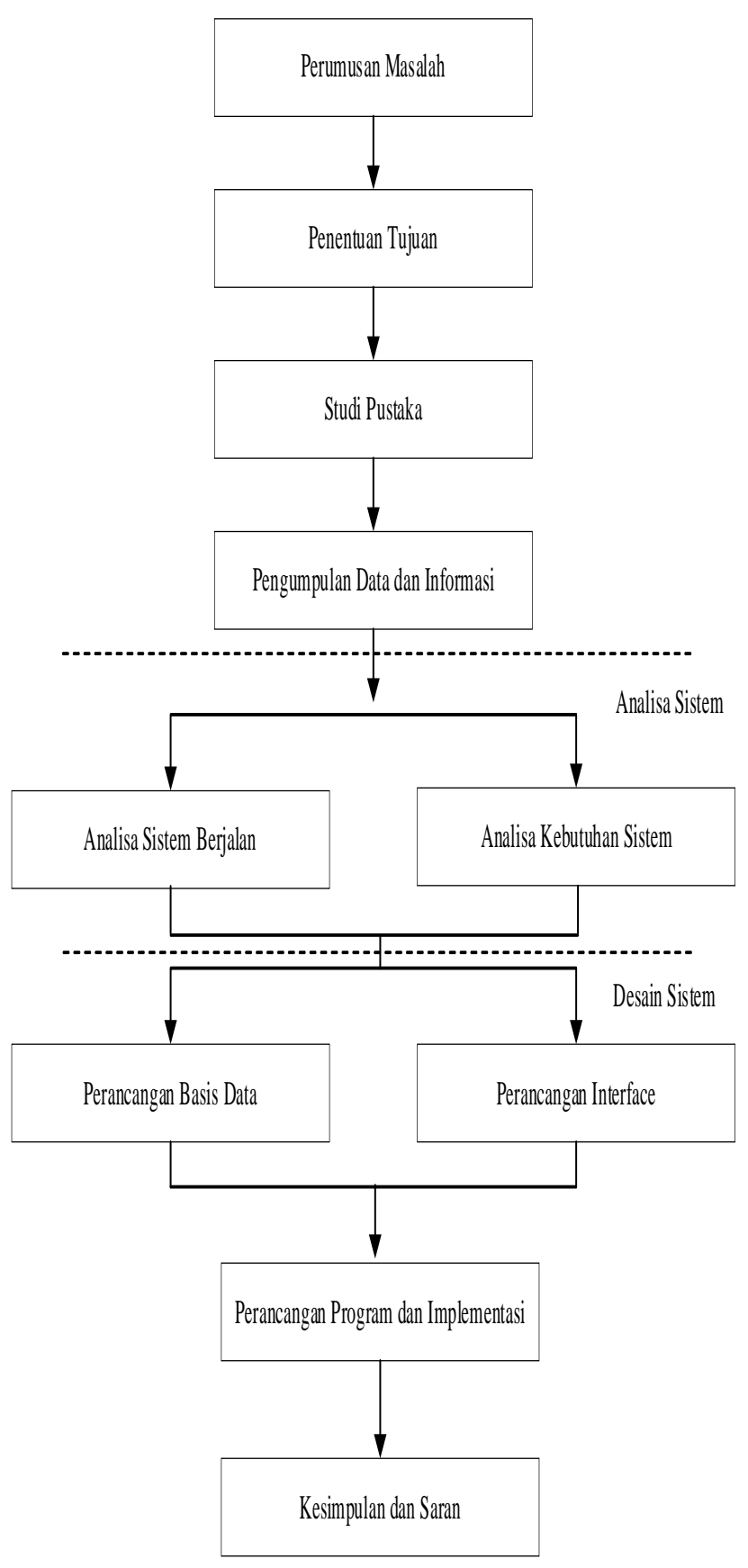

Gambar 1. Diagaram Alir Penelitian 
Penjelasan dari gambar diagram alir penelitian diatas, yaitu

\section{Perumusan Masalah}

Tahap pertama merumuskan masalah berdasarkan latar belakang yang telah dijelaskan.

2. Penentuan Tujuan

Tahap kedua menentukan tujuan penelitian, agar permasalahan yang terjadi mendapatkan solusi yang tepat dan berguna.

\section{Studi Pustaka}

Tahap ini dilakukan untuk menambah pengetahuan mengenai permasalahan yang dibahas dan untuk menentukan teori dan metode penelitian yang sesuai dalam menyelesaikan permasalahan yang terjadi. Peneliti menggunakan buku, jurnal, artikel dan laman yang berhubungan dengan penelitian tersebut.

4. Pengumpulan Data dan Informasi

\section{Hasil dan Pembahasan}

\section{A. Analisa Sistem Berjalan}

Pada Analisa bisnis yang sedang berjalan digunakan pendekatan metode agar memudahkan proses
Tahap selanjutnya menetapkan data dan informasi sebagai sumber data, penelitian ini menggunakan data primer dengan melakukan wawancara dan observasi di lapangan.

\section{Analisa Sistem}

Tahap analisa sistem dimulai dari analisa sistem berjalan dan analisa kebutuhan sistem yaitu membandingkan bisnis proses yang berjalan dengan kebutuhan sistem yang akan dibuat.

\section{Desain Sistem}

Tahap desain sistem merupakan perancangan basis data dan perancangan interface berhubungan dengan mockup. 7. Perancangan Program dan Implementasi

Tahap perancangan program berhubungan dengan desain input output sistem. Selanjutnya implementasi sistem yang telah dibuat kepada pengguna.

\section{Kesimpulan dan Saran}

Tahap terakhir kesimpulan yaitu ringkasan keputusan yang dihasilkan dari penelitian.

identifikasi. Metode Analisa yang digunakan adalah SWOT dengan memproyeksikan perbandingan sebelum dan sesudah dilakukan penelitian

Tabel 1 Analisis Swot sebelum Penelitian

\section{KEKUATAN (STRENGTH)}

1. Bangunan gedung yang luas dan memiliki banyak paviliun

2. Proses dilakukan secara langsung (just in time)

\section{KELEMAHAN ( WEAKNESSES)}

1. Kurangnya informasi atau iklan tentang paviliun

2. Proses pemesanan dan pembayaran tidak berbasis teknologi atau secara manual

3. Pengguna harus bertemu langsung dengan pengurus untuk melakukan transaksi

\section{ANCAMAN (THREATS)}

Banyaknya rumah kost yang sudah menggunakan aplikasi berbasis online
PELUANG (OPORTUNITIES)

1. Informasi atau iklan tentang paviliun dapat dibagikan pada platform yang dapat diakses oleh masyarakat pengguna internet

2. Proses pemesanan dan pembayaran dapat dilakukan secara online dan dengan transfer

3. Pengguna dapat melakukan transaksi dari jarak jauh

Tabel 2 Analisis Swot setelah Penelitian

\section{KEKUATAN (STRENGTH)}

1. Adanya system informasi berbasis online

2. Informasi atau iklan tentang paviliun tersedia pada website aplikasi

3. Proses pemesanan dapat dilakukan dari jarak jauh atau secara online

4. Proses pembayaran dapat dilakukan dengan transfer dan lebih aman

5. Pemilik dapat mengakses laporan paviliun dengan mudah

\section{KELEMAHAN (WEAK\ESSES)}

Diperlukan biaya yang cukup besar untuk menerapkan sistem informasi berbasis online 


\section{PELUANG (OPORTUNITIES)}

1. Proses pemesanan dan pembayaran dapat dilakukan secara online dan dengan transfer

2. Pengguna dapat melakukan transaksi dari jarak jauh
ANCAMAN (THREATS)

1. Banyak nya pesaing rumah kost online

2. Ancaman keamanan dari hacker
Pada Analisa bisnis yang sedang berjalan calon penyewa harus Mendatangi lokasi Paviliun Sejahtera, setelah itu calon penyewa bisa bertemu dengan pengelola untuk berdialog tentang syarat dan ketentuan Ketika akan memesan paviliun, dan melihat langsung keadaan paviliun beserta semua fasilitas nya. Jika sepakat calon penyewa bisa langsung melakukan pembayaran dan menyerahkan fotokopi KTP untuk keperluan data bagi pengelola, setelah itu calon penyewa menentukan tanggal kepindahan kemudian diberi kunci paviliun oleh pengurus.

\section{B. Analisa Proses Bisnis}

Analisis sistem yang sedang berjalan didefinisikan sebagai penguraian dari suatu sistem untuk mengindentifikasikan dan mengevaluasi permasalahan yang terjadi. Berikut ini flowchart tentang gambaran sistem penyewaan Paviliun Sejahtera.

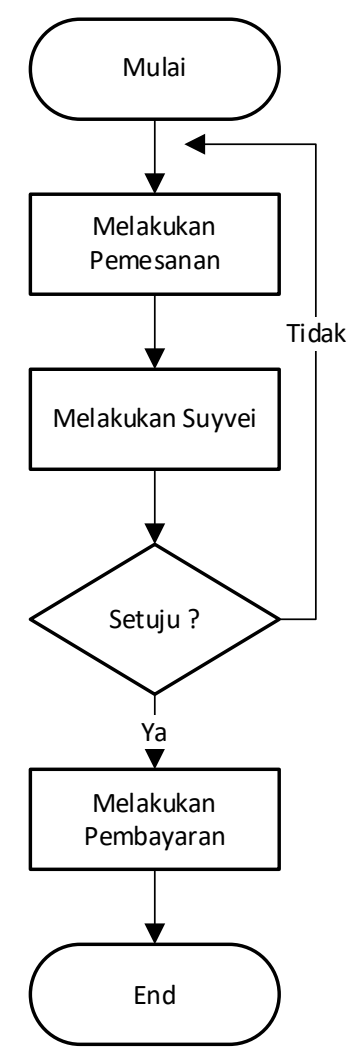

Gambar 2. Flowchart Sistem Sewa Paviliun Sejahtera

Deskripsi Sistem sewa Paviliun Sejahtera :

1. Calon penyewa berkunjung ke lokasi Paviliun Sejahtera

2. Calon penyewa bertemu dengan pengelola

3. Calon penyewa dan pengelola berdialog memberikan informasi

4. Calon penyewa malihat langsung keadaan Paviliun dan fasilitas yang tersedia

5. Jika calon penyewa setuju, calon penyewa langsung melakukan pembayaran

6. Penyewa diberikan Kwitansi oleh pengelola sebagai tanda bukti serah terima

7. Penyewa menyerahkan dokumen fotokopi KTP untuk data bagi pengurus

8. Pengurus menyerahkan kunci paviliun ke penyewa

\section{Perancangan UML}

Pemodelan UML (Unified Modeling Language) muncul karena adanya kebutuhan pemodelan visual untuk menspesifikasikan, menggambarkan, membangun, dan dokumentasi dari sistem perangkat lunak menggunakan diagram dan teks- teks pendukung. UML merupakan salah satu standar Bahasa yang banya digunakan didunia industri untuk mendefinisikan requirement, membuat analisis dan desain, serta menggambarkan arsitektur dalam pemrograman berorientasi objek.

\section{Use Case Diagram}


Diagram use case merupakan pemodelan untuk behavior sistem informasi yang akan dibuat. Menurut (Simarmata: 2013), Use case mendeskripsikan sebuah interaksi antara satu atau lebih aktor dengan sistem informasi yang akan dibuat. Dan untuk mengetahui fungsi apa saja yang ada didalam sebuah sistem informasi dan siapa saja yang berhak menggunakan fungsi tersebut.

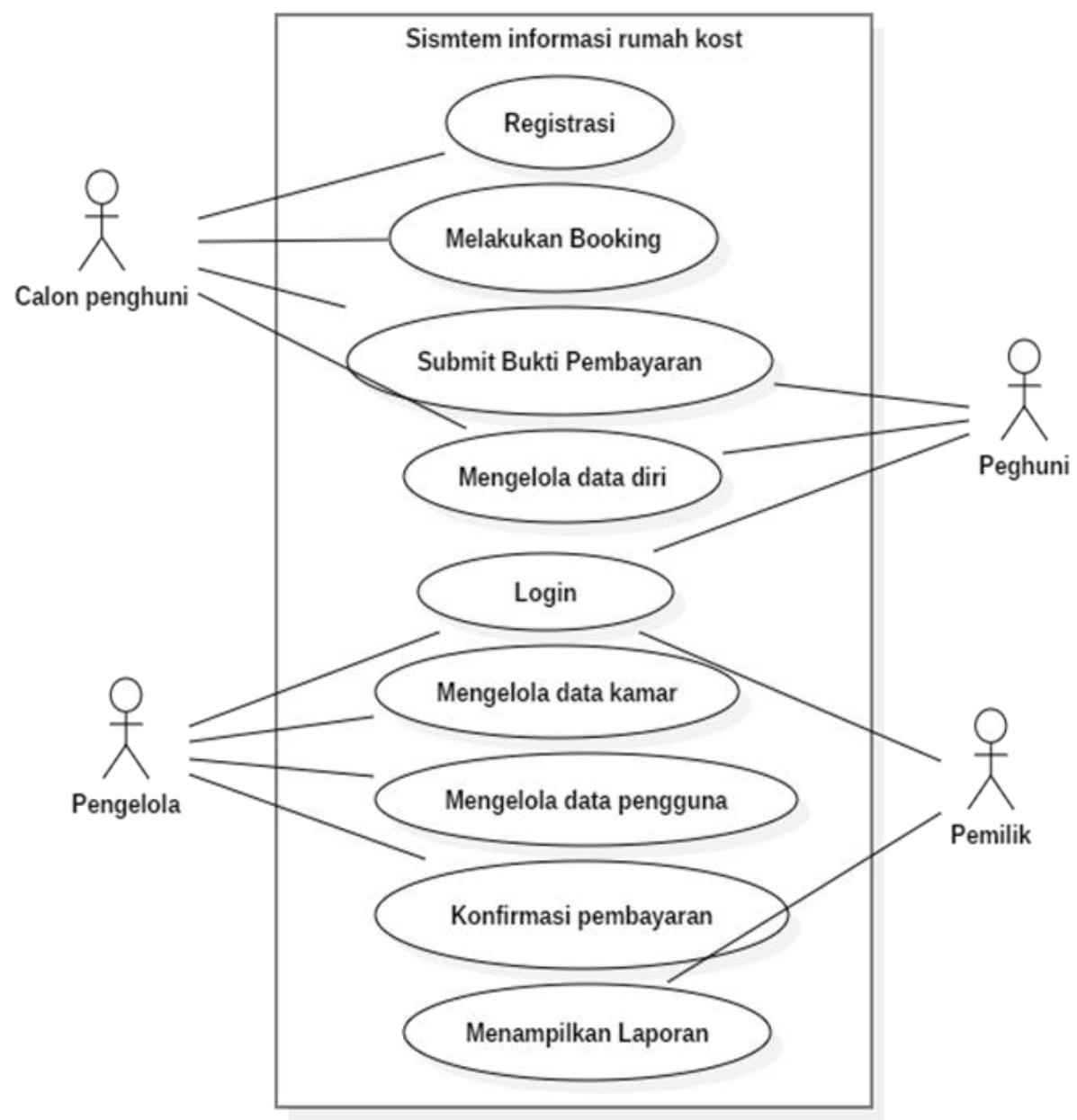

Gambar 3. Usecase Diagram Sistem Sewa Paviliun Sejahtera

Pada Gambar 3, mendeskripsikan dalam sistem sewa paviliun ini terdiri empat aktor yaitu calon penghuni yang nantinya naik level menjadi penghuni, pengelola, dan pemilik. 


\section{Class Diagram}

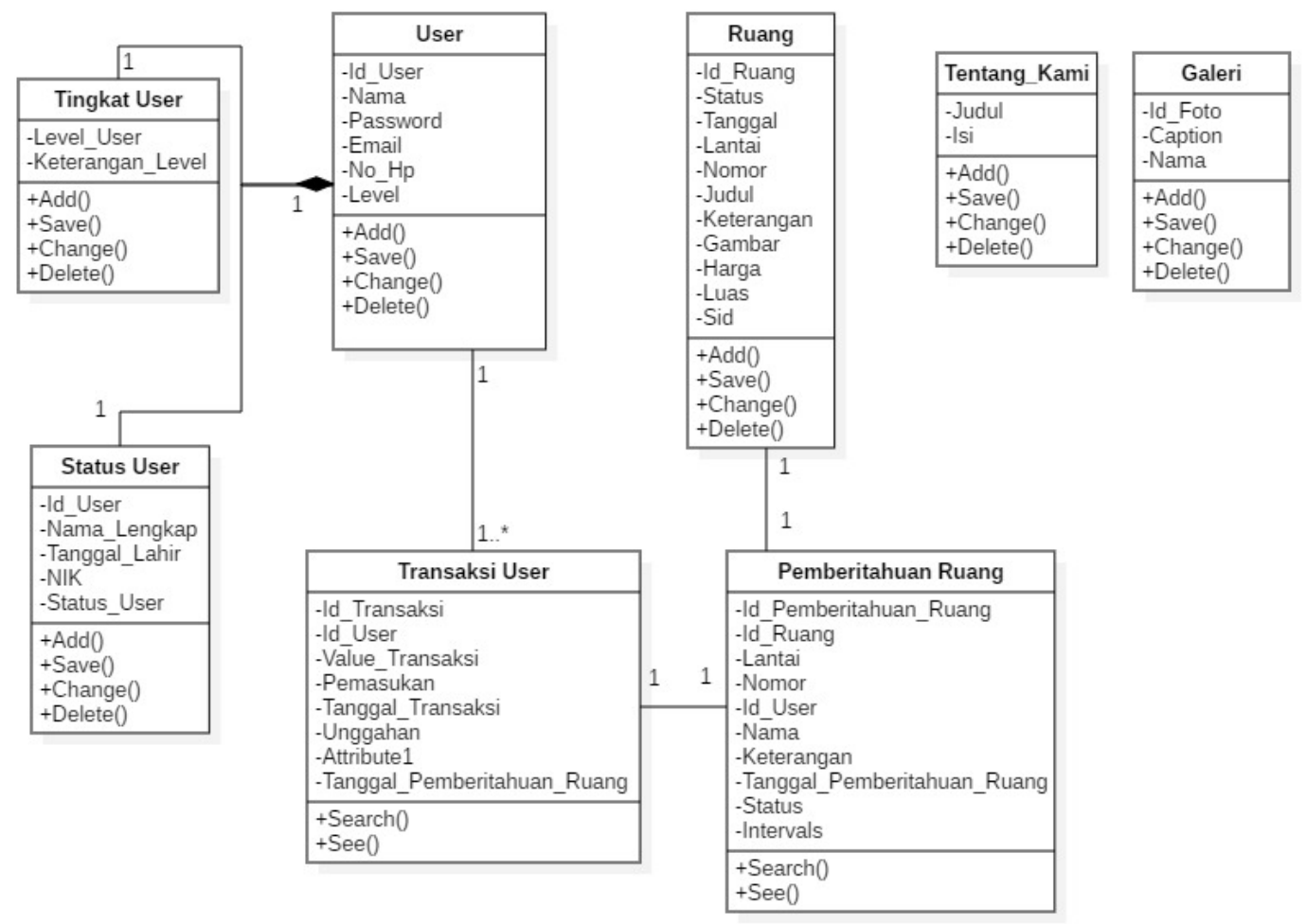

Gambar 4. Class Diagram

Pada Gambar 4 merupakan diagram Class yang D. Tampilan Antar Muka menjelaskan atribut dan operation dari setiap classnya.

1. Tampilan Awal Antarmuka "K.O.S

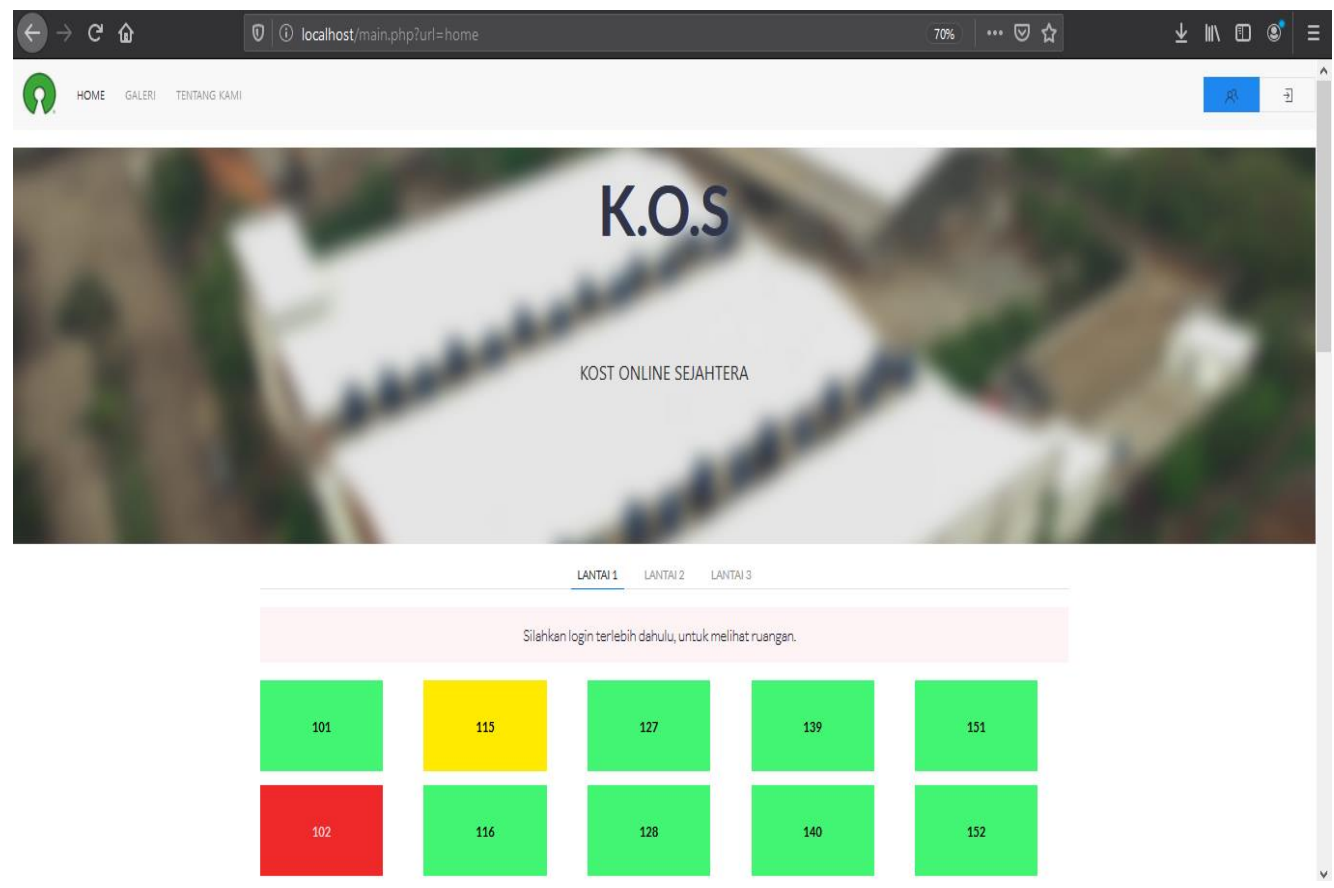

Gambar 5. Halaman Utama Aplikasi K.O.S

Gambar 5 adalah tampilan awal aplikasi kontrakan online sejahtera berbasis website. 
2. Tampilan Antarmuka Halaman Detail Paviliun

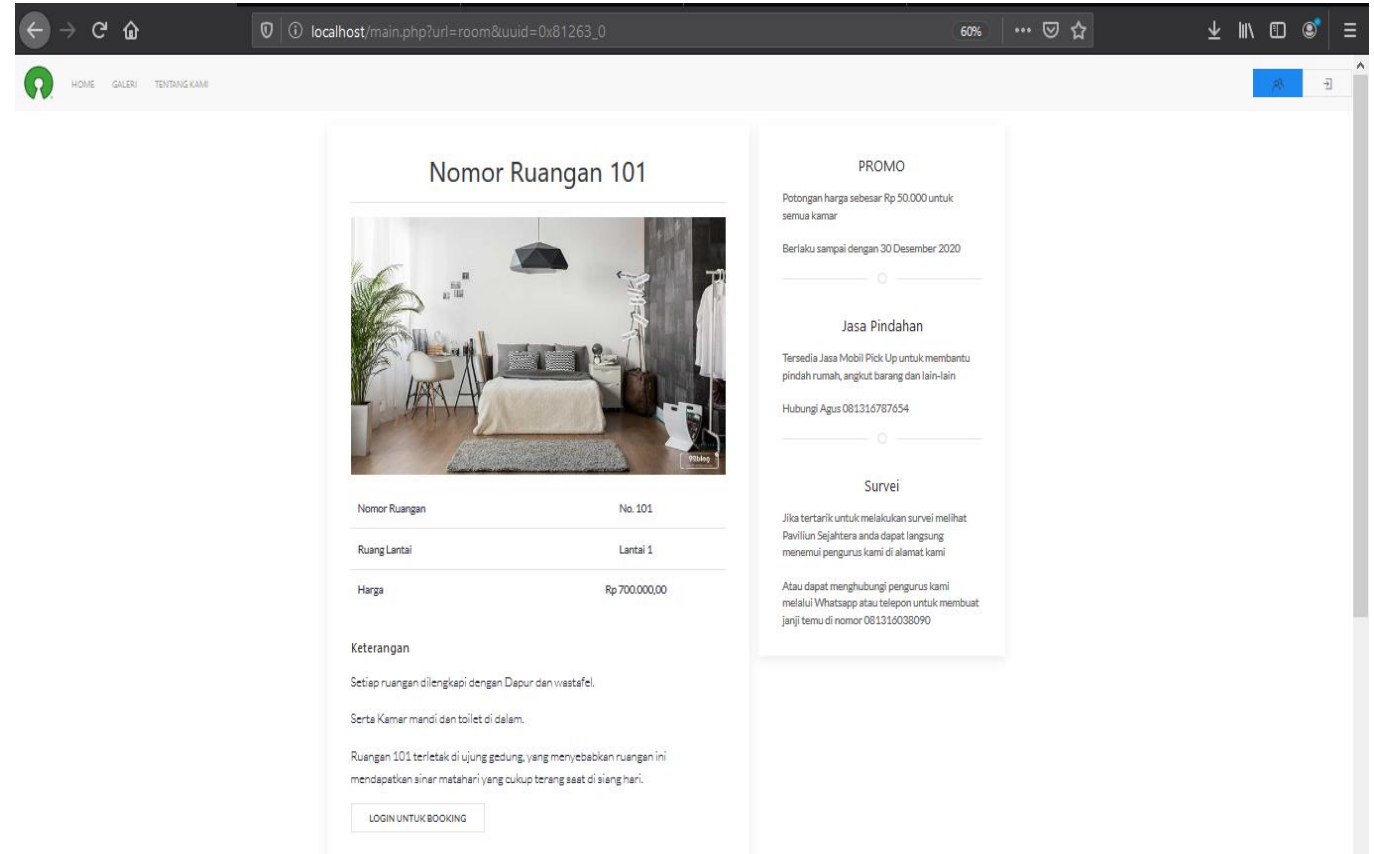

Gambar 6. Halaman Detail Paviliun

Gambar 6 adalah halaman detail paviliun, dimana pengunjung website dapat melihat keterangan detail tentang paviliun sebelum melakukan sewa.

3. Tampilan Antarmuka Halaman Registrasi

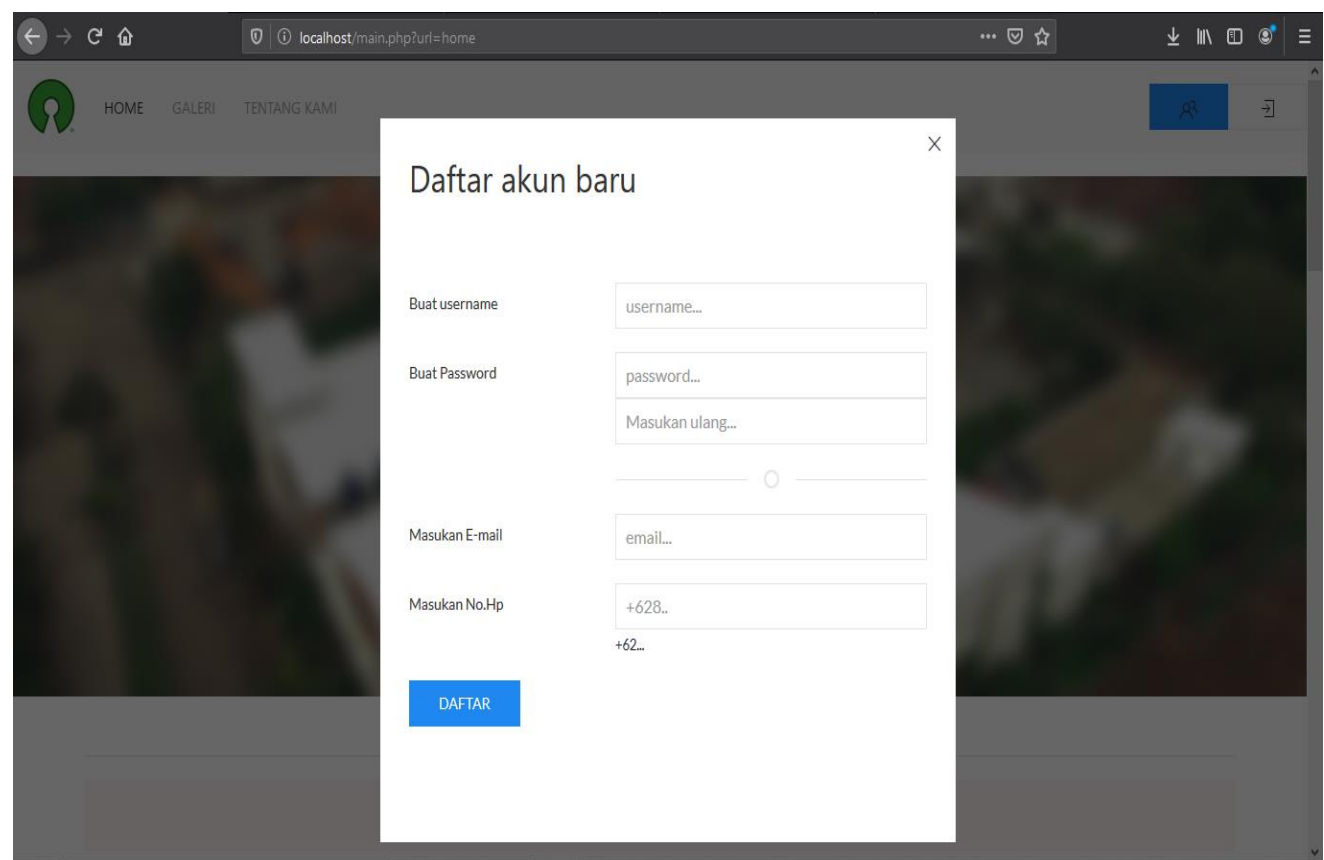

Gambar 7. Halaman Registrasi

Gambar 7 merupakan halaman registrasi, dimana user melakukan registrasi untuk sewa paviliun. 
4. Tampilan Antarmuka Booking

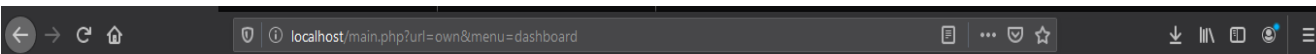

(R) home menu user galerl tentang kam

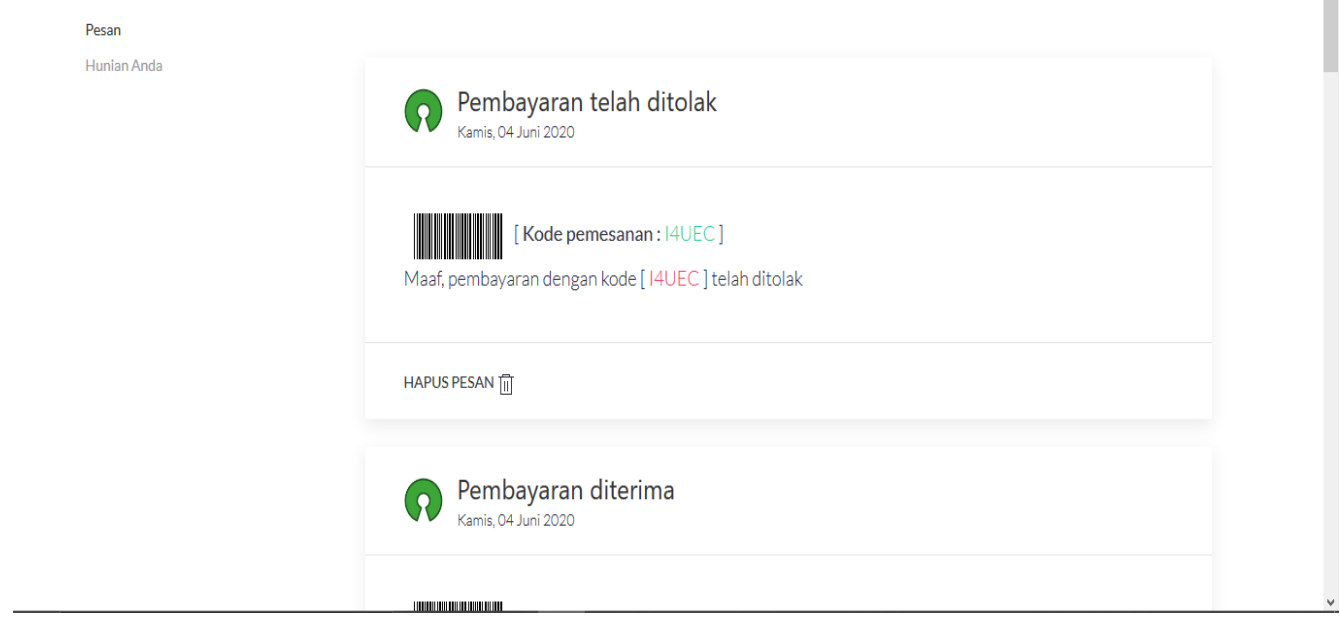

Gambar 8. Menu Booking

Gambar 8 merupakan halaman booking, dimana user melakukaan booking untuk sewa paviliun sebelum melakukan pembayaran.

\section{Kesimpulan}

Dari Hasil penelitian menunjukkan bahwa aplikasi berbasis web K.O.S ini dapat melakukan transaksi penyewaan paviliun dengan online tanpa harus datang langsung untuk melakukaan booking dan sewa. Untuk Saran peningkatan dan pengembangan penelitian ke depan, yaitu (1) Pembuatan aplikasi ini masih sederhana, diharapkan pengembangan selanjutnya dapat lebih menarik dan atraktif; (2) aplikasi ini diharapkan dapat berbasis android sehingga lebih easy to use.

\section{Daftar Pustaka}

[1] Faturrahman, Membuat Website Mudah dan Pratktis dengan Weebly, Jakarta: Elexmedia, 2014.
[2] Yurinda, Software Engineering, Yogyakarta: CV. Budi Utama, 2017.

[3] D. Setiawan, Buku Skati Pemrograman Web : HTML, CSS, PHP, MySQL, \& Javascript, Yogyakarta: PT. ANAK HEBAT INDONESIA, 2017.

[4] E. Irwansyah and M. V. Jurike, Pengantar Teknologi Informasi, Yogyakarta: deepublish, 2014.

[5] T. R, Manajemen Proyek Sistem Informasi, bagaimana mengoleh proyek sistem informasi secara efektif \& efisien, Yogyakarta: Andi Offset, 2012.

[6] Wardana, Aplikasi Website Profesional dengan PHP dan jQuery, Jakarta: PT. Elex Media Komputindo, 2016. S. Hartati dan S. Iswanti, Sistem Pakar dan Pengembangannya, Yogyakarta: Graha Ilmu, 2008. 